\title{
Accelerometry combined with heart rate telemetry in the assessment of total energy expenditure
}

\author{
H. Patrik Johansson ${ }^{1,2 *}$, Lena Rossander-Hulthén ${ }^{3}$, Frode Slinde ${ }^{3}$ and Björn Ekblom ${ }^{1,2}$ \\ ${ }^{1}$ The Åstrand Laboratory of Work Physiology, Stockholm University College of Physical Education and Sports, Box 5626, SE-114 86 \\ Stockholm, Sweden \\ ${ }^{2}$ Department of Physiology and Pharmacology, Karolinska Institutet, Stockholm, Sweden \\ ${ }^{3}$ Department of Clinical Nutrition, Sahlgrenska Academy at Göteborg University, Göteborg, Sweden
}

(Received 30 April 2004 - Revised 17 May 2005 - Accepted 20 May 2005)

\begin{abstract}
The aim of the present study was: (1) to develop a new method for total energy expenditure (TEE) assessment, using accelerometry (ACC) and heart rate (HR) telemetry in combination; (2) to validate the new method against the criterion measure (DLW) and to compare with two of the most common methods, FLEX-HR and ACC alone. In the first part of the study $\mathrm{V}_{\mathrm{O} 2}$, HR and ACC counts were measured in twenty-seven subjects during walking and running on a treadmill. Considering the advantages and disadvantages of the HR and ACC methods an analysis model was developed, using ACC at intensities of low and medium levels and HR at higher intensities. During periods of inactivity, RMR is used. A formula for determining TEE from ACC, HR and RMR was developed: $\mathrm{TEE}=1.1 \times\left(\mathrm{EQ}_{\mathrm{HR}} \times \mathrm{TT}_{\mathrm{HR}}+\mathrm{EQ}_{\mathrm{ACC} 1} \times \mathrm{TT}_{\mathrm{ACC} 1}+\mathrm{EQ}_{\mathrm{ACC} 2} \times \mathrm{TT}_{\mathrm{ACC} 2}+\mathrm{RMR} \times \mathrm{TT}_{\mathrm{RMR}}\right)$. In the validation part of the study a sub-sample of eight subjects wore an accelerometer, HR was logged and TEE was measured for $14 \mathrm{~d}$ with the DLW method. Analysis of the Bland-Altman plots with $95 \%$ CI indicates that there are no significant differences in TEE estimated with HR-ACC and ACC alone compared with TEE measured with DLW. It is concluded that the HR-ACC combination as well as ACC alone has potential as a method for assessment of TEE during free-living activities as compared with DLW.
\end{abstract}

Physical activity: Motion sensor: FLEX heart rate: Doubly labelled water

Clear evidence today indicates that regular physical activity (PA) and physical fitness promote health and longevity. Higher levels of total energy expenditure (TEE) significantly predicts decreased risk of CHD and many other diseases including cancer (Lee et al. 2000; Thune \& Furberg, 2001; Farahmand et al. 2003; World Health Organization, 2003). While important factors linked to increased health risks for these diseases such as hyperlipidaemia, hypertension, smoking and obesity are easily quantified and exhibit a fairly high day-to-day stability, another important health factor, PA, not only shows high day-to-day variation but is also very hard to assess in free-living situations (Montoye et al. 1996).

A number of methods have been developed in order to quantify PA and energy expenditure (EE) in free-living situations. The assessment methods can be divided mainly into self-reported and objective methods. The former include, for example, activity diaries, dietary records, questionnaires and interviews, while the objective measurement techniques include measures such as heart rate (HR) recording, accelerometry (ACC) and the doubly labelled water (DLW) method.

It is a well-known fact that the linear relationship between $\mathrm{V}_{\mathrm{O} 2}$ and HR opens up the possibility to assess EE by HR recordings. However, at lower sub-maximal intensities factors such as fear, excitement and related emotional stress, as well as mode, duration and type of PA may cause an elevated HR above that explained by energy turnover (Åstrand \& Rodahl, 1986). Since the $\mathrm{V}_{\mathrm{O} 2}-\mathrm{HR}$ relationship is dependent upon a number of factors, such as physical fitness, maximal HR, gender and age, individual calibration tests must be performed to estimate EE from a formula based on the $\mathrm{V}_{\mathrm{O} 2}-\mathrm{HR}$ relationship. The within-person correlation between $\mathrm{HR}$ and $\mathrm{V}_{\mathrm{O} 2}$ frequently exceeds 0.95 (Haskell et al. 1993). However, when the method was used to assess EE in the field it was concluded that the HR technique overestimated EE by $12.3 \%$ compared with DLW (Emons et al. 1992). One reason for the discrepancy could be that the regression equations developed from use of large muscle groups is also used when predicting EE levels on small muscle group activity. Another explanation is the non-linear relationship between $\mathrm{HR}$ and $\mathrm{V}_{\mathrm{O} 2}$ at low intensities as mentioned earlier.

An alternative way to assess EE data from HR recordings is to use the FLEX-HR method. In calibration tests, each subject is monitored simultaneously for $\mathrm{HR}$ and $\mathrm{V}_{\mathrm{O} 2}$ while lying down, sitting, standing and performing exercise of different intensities. RMR is measured or calculated. The FLEX-HR point is commonly defined as the average between the highest resting HR and the lowest $\mathrm{HR}$ obtained during exercise. If a HR recording 
is above the FLEX-HR point, the $\mathrm{HR}-\mathrm{V}_{\mathrm{O} 2}$ equation is used to obtain EE. If the HR value is below FLEX-HR, RMR is used (Ceesay et al. 1989). To avoid the influence of the non-linear portion of the $\mathrm{HR}-\mathrm{V}_{\mathrm{O} 2}$ relationship, an alternative FLEX-HR definition is often used. This alternative cut-off point is defined as FLEX-HR +10 beats/min. Thus, HR values below FLEX-HR and FLEX-HR +10 beats/min are substituted by RMR. However, since a large part of daily life results in HR above resting and below lowest exercise HR, this may be a large source for miscalculations. The FLEX-HR method has been validated against DLW in adults with normal activity levels (Heini et al. 1991, 1996; Davidson et al. 1997) and has shown acceptable levels of agreement in group estimates of TEE. However, the precision in individuals is inadequate with an error of about $20 \%$.

The ACC-based method relies on the fact that when a person moves, the EE increases proportionally to the muscular activity that accelerates the body and limbs. By recording the body movement over a period of time an estimate of energy expended can be assessed. The commercially available accelerometers are small in size, lightweight, do not interfere with the subjects' freedom of movement and can store data continuously over long periods of time. In laboratory settings a relatively strong relationship between ACC counts at locomotion and EE has been established (Melanson \& Freedson, 1995; Eston et al. 1998; Freedson et al. 1998; Trost et al. 1998; Leenders et al. 2003; Rowlands et al. 2004). However, under free-living conditions, when the movement pattern is more complex the relationship is not as convincing as shown when the uniaxial accelerometer Caltrac was validated against DLW in a study by Johnson et al. (1998). In that study it was concluded that energy expense estimated by Caltrac was significantly higher than the EE measured with DLW. Recently, Ekelund et al. showed a correlation of $0.39(P<0.05)$ between activity counts from the uniaxial CSA accelerometer (presently known as the MTI Actigraph) and total EE assessed with DLW during a $14 \mathrm{~d}$ period in twenty-six children (Ekelund et al. 2001). On the other hand, others showed that physical activity energy expenditure (PAEE) determined from the CSA activity counts was significantly underestimated by $59 \%$ compared with DLW (Leenders et al. 2001). In the latter study a general calibration equation, derived by Freedson et al. (1998) under controlled laboratory conditions, was used to predict PAEE from activity counts.

The main disadvantage of ACC-based motion sensors is the inability to detect certain types of PA. An accelerometer attached at the most common sites - the hip or lower back - cannot properly detect isolated limb motion, static work or cycling. Brage et al. (2003) recently showed that the relationship between activity counts and speed is linear in the walking range but not in running. In addition, the accelerometer is unable to distinguish between graded and level walking.

The two aforementioned field methods used for assessing PA and estimating EE have some limitations. A few studies have investigated the possibility to use a combination of HR recordings and motion sensors. Strath et al. used two motion sensors, arm and leg mounted, to distinguish between upper- or lower-body work. Using two different $\mathrm{HR}-\mathrm{V}_{\mathrm{O} 2}$ regression equations, one in reference to upper-body work and the other lower-body work, EE was calculated from HR telemetry data. The simultaneous HR-motion sensor technique showed a significantly stronger relationship with $\mathrm{V}_{\mathrm{O} 2}\left(R^{2} 0 \cdot 81\right)$ in comparison with the FLEXHR method $\left(R^{2}\right.$ 0.63). Haskell et al. (1993) also examined the possibilities of using arm- and leg-mounted motion sensors combined with HR recording and found that the combination was superior to the individual methods under laboratory conditions. Furthermore, both Rennie et al. (2000) and Brage et al. (2004) have used a combination between movement data and HR recording to assess TEE. In the study by Rennie et al. (2000) a combined, not commercially available, motion sensor and HR monitor were used, whereas Brage et al. (2004) used a CSA accelerometer and a Polar HR monitor in combination. Both studies were conducted in a calorimetry chamber during $22-24 \mathrm{~h}$ and found that a combination of motion sensors and HR monitoring were better than either model alone. Brage et al. (2004) also put in a lot of effort evaluating the use of individual compared with group calibration.

The DLW method has never been validated in free-living conditions. At present it is impossible to do so since there is no suitable criterion method. Under controlled conditions (respiration chamber, continuous $\mathrm{V}_{\mathrm{O} 2}$ measurement), however, validation studies show an accuracy of within $\pm 5 \%$ (Westerterp et al. 1988; Seale et al. 1993). Even though the method has never been validated under free-living conditions, it is still considered the 'golden standard' method under these circumstances. The main disadvantage with this method is still the cost of the ${ }^{18} \mathrm{O}$ and the expensive analysis methods. As a consequence, the method is mainly used in studies conducted on small groups. Another disadvantage is that the method only gives information on TEE and is unable to show different levels of intensity, frequency and duration of PA. However, the DLW method is undeniably ideal when used as a criterion measure for validating other field techniques for assessment of EE.

The main objective of the current study is to present a method using combined HR, ACC and RMR measurements in order to increase the validity of the energy turnover calculations. By combining $\mathrm{HR}$ and $\mathrm{ACC}$ recordings and using RMR for resting EE, considering corresponding advantages and limitations, a method for data analysis is proposed and validated against the criterion measure DLW.

\section{Method}

\section{Study design}

This is a two-part study. In the first part a new way of assessing EE by combining HR telemetry and ACC, using RMR for resting EE, is developed and presented. The purpose of the second part is, primarily, to validate the new method against the DLW method and, second, to compare the new method with the traditional FLEX-HR method and EE estimated from motion sensor data alone.

\section{Subjects}

Fourteen men (32.0 (SD 12.8) years; 186 (SD 6.8) cm; 86.1 $(\mathrm{SD} 14.8) \mathrm{kg}$ ) and thirteen women (26.6 (SD 5.3) years; 168 (SD 6.2) $\mathrm{cm} ; 63.9(\mathrm{SD} 9.7) \mathrm{kg}$ ) volunteered to take part in the study. As seen from the anthropometrical and physiological data in Table 1 , both normal and overweight (BMI > 25) as well as fit and unfit subjects were used in the present study. Before the study started the subjects were familiarized with the test methods used.

A sub-sample of six men (range: $28-63$ years; $166-188 \mathrm{~cm}$; $65 \cdot 7-120.5 \mathrm{~kg}$ ) and two women (28 and 30 years; 167 and $177.5 \mathrm{~cm} ; 61.2$ and $68.5 \mathrm{~kg}$ ) were recruited to take part in the 
Table 1. Descriptive statistics for all subjects

(Mean values and standard deviations)

\begin{tabular}{|c|c|c|c|c|c|c|c|c|c|}
\hline & \multicolumn{3}{|c|}{ Men $(n 14)$} & \multicolumn{3}{|c|}{ Women (n 13) } & \multicolumn{3}{|c|}{ Combined (n 27) } \\
\hline & Mean & SD & Range & Mean & SD & Range & Mean & SD & Range \\
\hline Age (years) & $32 \cdot 0$ & $12 \cdot 8$ & $23-63$ & $26 \cdot 6$ & $5 \cdot 3$ & $20-41$ & 29 & $10 \cdot 1$ & $20-63$ \\
\hline Height (cm) & $186 \cdot 0$ & $6 \cdot 8$ & $166-197$ & $168 \cdot 4$ & $6 \cdot 2$ & $158-180$ & $178 \cdot 0$ & $11 \cdot 2$ & $158-197$ \\
\hline Body weight (kg) & $86 \cdot 1$ & $14 \cdot 8$ & $65 \cdot 7-120 \cdot 5$ & $63 \cdot 9$ & $9 \cdot 7$ & $50 \cdot 4-88 \cdot 6$ & $75 \cdot 4$ & $16 \cdot 8$ & $50 \cdot 4-120 \cdot 5$ \\
\hline BMI $\left(\mathrm{kg} / \mathrm{m}^{2}\right)$ & $24 \cdot 8$ & $4 \cdot 2$ & $20 \cdot 9-36 \cdot 0$ & $22 \cdot 4$ & $3 \cdot 1$ & $18 \cdot 1-30 \cdot 5$ & $23 \cdot 7$ & 3.8 & $18 \cdot 1-36 \cdot 0$ \\
\hline $\mathrm{V}_{\mathrm{O} 2 \max }(\mathrm{ml} / \mathrm{kg}$ per $\min )$ & $51 \cdot 8$ & $7 \cdot 8$ & $40 \cdot 4-66 \cdot 2$ & $46 \cdot 6$ & 4.4 & $41 \cdot 8-54 \cdot 4$ & $49 \cdot 3$ & $6 \cdot 8$ & $40 \cdot 4-66 \cdot 2$ \\
\hline
\end{tabular}

For details of subjects and procedures, see p. 632.

validation of the new method (see also Table 2). Originally another two female subjects took part in the validation part of the present study but they had to be excluded due to undetected malfunction during the initiation of the motion sensor.

All subjects were instructed to refrain from eating, smoking and intake of caffeine at least $4 \mathrm{~h}$ prior to testing. They were also asked not to perform any strenuous exercise within $12 \mathrm{~h}$ before testing.

This project was approved by the Human Ethics Committee at The Karolinska Institute, Stockholm, Sweden. The experimental procedures, possible risks and benefits were explained to the subjects before their written consent was obtained. The project was conducted in accordance with the World Medical Association Declaration of Helsinki.

\section{Oxygen uptake}

RMR was measured early in the morning after an overnight fast. Following a $20 \mathrm{~min}$ bed rest, expired air was collected in duplicate Douglas bags. The collecting period was approximately $10 \mathrm{~min}$ for each bag. Collected air was analysed regarding $\mathrm{O}_{2}$ content (Oxygen Analyzer S-3A; Applied Electrochemistry Inc., Sunnyvale, CA, USA) and $\mathrm{CO}_{2}$ (Medical Gas Analyzer LB-2; Beckman Instruments International S.A., Geneva, Switzerland). Expired air volume was measured using a 120-litre wet spirometer (Collins P-1700-120 Liter Gasometer; Warren E. Collins Inc., Braintree, MA, USA). Prior to analysis gas analysers were calibrated using verified calibration gas of known concentration (Air Liquid Gas AB, Kungsängen, Sweden) and ambient air. The lowest individual $\mathrm{V}_{\mathrm{O} 2}$ values obtained were used as RMR. $\mathrm{V}_{\mathrm{O} 2}$ values were transformed to EE using the Weir formula, originally developed in 1949 (Weir, 1990).
During exercise expired air was analysed continuously with an automated metabolic gas analysis system (AMIS 2001; Innovision A/S, Odense, Denmark) evaluated by others (Jensen et al. 2002). The gas analysers were calibrated before each test using verified calibration gas of known concentration (Air Liquid Gas AB) and the flow meter was calibrated against a 3.0-litre syringe (Hans Rudolph Inc., Kansas City, MO, USA). Calibration procedures described by the manufacturer were otherwise followed.

\section{Heart rate monitors and motion sensor}

During exercise tests HR was recorded every $15 \mathrm{~s}$ using a Polar HR meter (Vantage NV, Polar Electro OY, Kempele, Finland), consisting of an electrode-belt transmitter worn around the chest and a wrist-mounted receiver. During the validation (second) part of the study the HR recording interval was set to $1 \mathrm{~min}$. ACC counts were measured with an uniaxial accelerometer, the MTI Actigraph (model 7164; Manufacturing Technology Inc., Fort Walton Beach, FL, USA), formerly known as the CSA activity monitor. The MTI Actigraph is a small $(51 \times 41 \times 15 \mathrm{~mm})$, lightweight $(42.5 \mathrm{~g})$ accelerometer that is designed to measure and record time-varying accelerations ranging in magnitude from approximately 0.05 to $2 \mathrm{G}$. The accelerometer is band limited with a frequency response from $0 \cdot 25$ to $2.5 \mathrm{~Hz}$. These parameters are chosen by the manufacturer to detect human motion and to filter out high-frequency movements such as vibrations. The MTI Actigraph was secured directly to the skin in a lower back position (lumbar vertebrae four to five) using an elastic strap. In the calibration part of the present study, the user-specified sampling period (epoch) was set to $15 \mathrm{~s}$. During the validation part the epoch was $1 \mathrm{~min}$ and at this setting the MTI Actigraph is capable of collecting consecutively $22 \mathrm{~d}$ of data (Manufacturing Technology Inc., 2003). Periods when the devices were not used were detected through prolonged periods of no HR value and motion sensor output 0 . In addition, subjects were

Table 2. Descriptive statistics for the subjects taking part in the validation study (Mean values and standard deviations)

\begin{tabular}{|c|c|c|c|c|c|c|c|c|c|}
\hline & \multicolumn{3}{|c|}{ Men $(n 6)$} & \multicolumn{3}{|c|}{ Women (n 2) } & \multicolumn{3}{|c|}{ Combined $(n 8)$} \\
\hline & Mean & SD & Range & Mean & $\mathrm{SD}$ & Range & Mean & SD & Range \\
\hline Age (years) & $41 \cdot 7$ & $15 \cdot 6$ & $30-63$ & $29 \cdot 0$ & 1.4 & $28-30$ & 38.5 & $14 \cdot 4$ & $28-63$ \\
\hline Height $(\mathrm{cm})$ & $179 \cdot 6$ & 9.9 & $166-188$ & $172 \cdot 3$ & $7 \cdot 4$ & $167-177$ & $177 \cdot 8$ & 9.5 & $166-188$ \\
\hline Body weight (kg) & $80 \cdot 4$ & $20 \cdot 3$ & $65 \cdot 7-120 \cdot 5$ & $64 \cdot 9$ & $5 \cdot 2$ & $61 \cdot 2-68 \cdot 5$ & 76.5 & $18 \cdot 7$ & $61 \cdot 5-120 \cdot 5$ \\
\hline BMI $\left(\mathrm{kg} / \mathrm{m}^{2}\right)$ & 24.9 & $5 \cdot 6$ & $21 \cdot 2-36 \cdot 0$ & 21.8 & 0.1 & $21 \cdot 7-21.9$ & $24 \cdot 1$ & 4.9 & $21 \cdot 2-36 \cdot 0$ \\
\hline Body fat (\%) & $21 \cdot 3$ & $9 \cdot 0$ & $11.6-34.5$ & 21.7 & 0.7 & $21 \cdot 2-22 \cdot 2$ & 21.4 & $7 \cdot 6$ & $11.6-34.5$ \\
\hline $\mathrm{V}_{\mathrm{O} 2 \max }(\mathrm{ml} / \mathrm{kg}$ per min $)$ & $53 \cdot 2$ & $10 \cdot 1$ & $39.5-65 \cdot 1$ & $51 \cdot 0$ & $2 \cdot 2$ & $49 \cdot 5-52 \cdot 6$ & $52 \cdot 6$ & $8 \cdot 3$ & $39 \cdot 5-65 \cdot 1$ \\
\hline
\end{tabular}

For details of subjects and procedures, see p. 632. 
instructed to note time-points when the devices were taken on or off. During both the calibration and the validation an external time piece was used to synchronize the internal clocks of the ACC, the HR monitor and the metabolic gas analysis system.

\section{Body composition}

Before and after the test period body composition was assessed in all subjects using the underwater weighing technique. The method applies Archimedes' principle by comparing the mass of a subject in air and under water. Subjects are instructed to exhale as much as possible before being submerged and weighed on a scale attached to a specially constructed tank. In order to minimize errors caused by inability to full exhalation this procedure is repeated ten times and an average of the last five measurements is used. Using the mass in air and whilst submerged, with corrections made for residual gas volume in the lungs, gastrointestinal gas and water temperature, body density is calculated (Brodie \& Stewart, 1999). The percentage body fat is subsequently calculated applying the Siri equation (Siri, 1956).

\section{Doubly labelled water}

Sample analysis and calculation procedures have been described elsewhere (Slinde et al. 2003). Urine samples were analysed in triplicate on a Finnigan MAT Delta Plus Isotope-Ratio Mass Spectrometer (ThermoFinnigan, Uppsala, Sweden).

\section{Procedures}

In the validation (second) part of the present study each subject wore an accelerometer and a HR monitor for $14 \mathrm{~d}$. The criterion measure was the DLW method. Subjects were instructed only to take off the devices during sleep, showering and bathing. HR data were downloaded every third day. TEE from the DLW method was measured over a period of $14 \mathrm{~d}$. At day 1 , a baseline urine sample was collected for determination of background isotope enrichment. Then the subjects ingested a weighed mixture of deuteriated and ${ }^{18} \mathrm{O}$-enriched water, corresponding to $0.05 \mathrm{~g}^{2} \mathrm{H}_{2} \mathrm{O}$ and $0 \cdot 10 \mathrm{~g} \mathrm{H}_{2}^{18} \mathrm{O}$ per $\mathrm{kg}$ body weight. Seven urine samples were collected by a member of the research group and the exact voiding time was registered on days $2,3,4,8,13,14$ and 15 . TEE from the DLW method (TEE DLW) was calculated by the multi-point method by linear regression from the difference between elimination constants of ${ }^{2} \mathrm{H}$ and ${ }^{18} \mathrm{O}$, with the assumptions for fractionating and a respiratory quotient of 0.85 (International Atomic Energy Agency, 1990). The relationship between pool size ${ }^{2} \mathrm{H}\left(N_{\mathrm{D}}\right)$ and pool size ${ }^{18} \mathrm{O}\left(N_{\mathrm{O}}\right)$ was used as a quality measurement of the DLW analysis as proposed by International Atomic Energy Agency (1990).

\section{Calibration}

To establish the relationship between ACC counts, HR and steady-state $\mathrm{V}_{\mathrm{O} 2}$, subjects performed 4 min each of the following exercise conditions on a motorized treadmill (RL 1500E; Rodby Innovation $\mathrm{AB}$, Enhörna, Sweden): sitting; standing; walking at 2 , 4 and $6 \mathrm{~km} / \mathrm{h}$; running at $10 \mathrm{~km} / \mathrm{h}$. Thereafter, an incremental test for establishing maximal aerobic power $\left(\mathrm{V}_{\mathrm{O} 2 \max }\right)$ was performed. The starting point was $8-10 \mathrm{~km} / \mathrm{h}$ level running, depending on physical fitness, followed by a minute-by-minute elevation of grade and speed until subjective exhaustion. $\mathrm{V}_{\mathrm{O} 2}$, HR and ACC were continuously recorded. Levelling-off regarding $\mathrm{V}_{\mathrm{O} 2} v$. rate of work and $\mathrm{RER} \geq 1.15$ were used as criteria for establishing $\mathrm{V}_{\text {O2max }}$ (Åstrand \& Rodahl, 1986).

\section{Data processing and statistical analysis}

All accelerometer and HR monitor data were downloaded to a personal computer and were processed using a standard spreadsheet program (Microsoft Excel 2000; Microsoft Corporation, Redmond, WA, USA). All statistical analysis was performed using SPSS for Windows, version 11.0 (SPSS, Chicago, IL, USA). Descriptive statistics were performed on each variable and modified Bland-Altman plots (Bland \& Altman, 1986) with $1.96 \times$ SD and $95 \%$ CI indicated were used to detect differences between TEE and PAEE $/ \mathrm{kg}$ assessed with the different methods. The presence of heteroscedasticity was examined and quantified using Bland-Altman plots together with Pearson's correlation (Atkinson \& Nevill, 1998). Model precision differences were tested using root mean square error (RMSE) with $95 \% \mathrm{CI}$. PAEE $/ \mathrm{kg}$ was calculated as $((\mathrm{TEE} \times 0.9)-\mathrm{RMR}) /$ body weight.

\section{Results}

$\mathrm{V}_{\mathrm{O} 2}$, ACC and HR data from the calibration tests are presented in Table 3. One representative example for the group, considering the relationship between $\mathrm{V}_{\mathrm{O} 2}$ and $\mathrm{HR}$ obtained, is shown in Fig. 1(A). There is a clear linear $\mathrm{V}_{\mathrm{O} 2}-\mathrm{HR}$ relationship at medium and high intensities while the relationship at lower intensity levels is less accurate. A low heart rate cut-off point (COHR) that separates the lower non-linear $\mathrm{V}_{\mathrm{O} 2}-\mathrm{HR}$ portion from the linear relation that exists at higher intensities is defined as the average between the lowest working HR (walking at $2 \mathrm{~km} / \mathrm{h}$ )

Table 3. Heart rate, oxygen uptake and activity counts to all activities performed in the laboratory by all subjects (sitting and standing not included; $n$ 27) (Mean values and standard deviations)

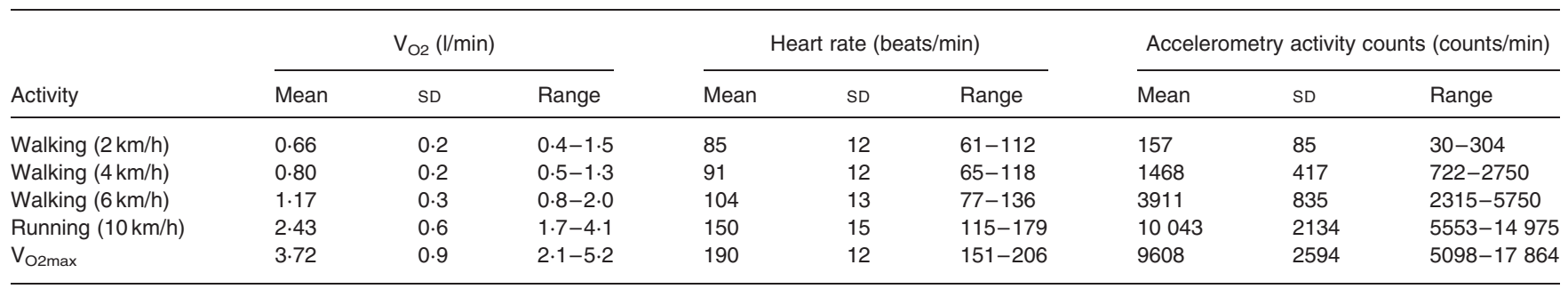

For details of subjects and procedures, see p. 632 . 


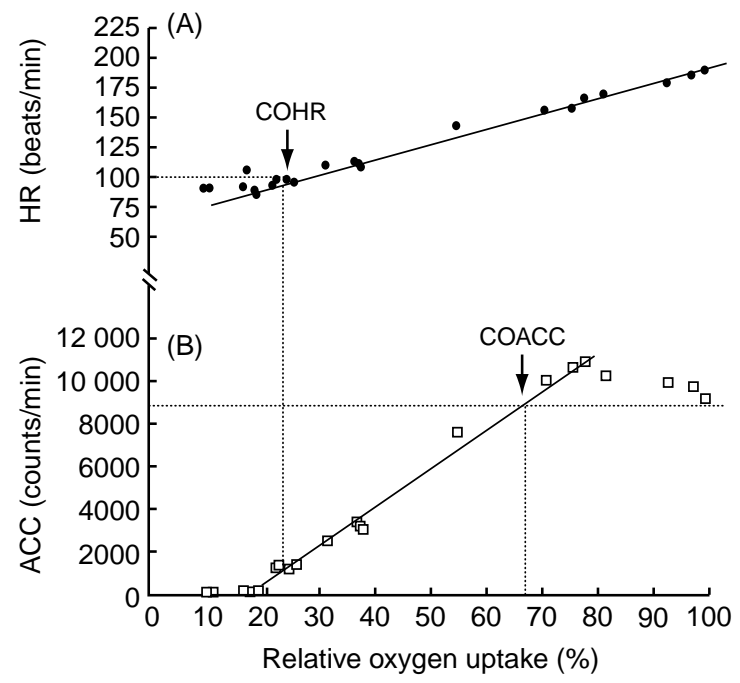

Fig. 1. Accelerometry activity counts $(A C C)$, heart rate $(H R)$ and percentage of $\mathrm{V}_{\mathrm{O} 2 \mathrm{max}}$ for one of the subjects. COACC, accelerometer cut-off point; COHR, HR cut-off point.

and the highest HR during rest (standing or sitting) +10 beats/ min. The same cut-off points were used for the calculations of TEE FLEX-HR. COHR in the twenty-seven subjects varied between 68 and 118 beats/min (median: 90 beats $/ \mathrm{min}$ ), corresponding to between 13.5 and $26.7 \%$ of $\mathrm{V}_{\mathrm{O} 2 \max }$ (median: $21.9 \%$ ).

ACC counts and corresponding $\mathrm{V}_{\mathrm{O} 2}$ values of the same subject are shown in Fig. 1(B). ACC counts first increase linearly with $\mathrm{V}_{\mathrm{O} 2}$ from sitting rest up to about 200 counts/min (walking at $2 \mathrm{~km} / \mathrm{h}$ ) and then up to about $75 \%$ of $\mathrm{V}_{\mathrm{O} 2 \max }$, thus producing two $\mathrm{V}_{\mathrm{O} 2}-\mathrm{ACC}$ linear equations (see Fig. 2). Above this point ACC levels off or decreases. An upper accelerometer cut-off point (COACC) is graphically determined as illustrated in Fig. 1(B). In twenty-five out of twenty-seven subjects the COACC varied between 5100 and 13500 counts/min (median: 9700) corresponding to between 32.0 and $69.4 \%$ of $\mathrm{V}_{\mathrm{O} 2 \max }$ (median: $48.7 \%$ ). In the remaining two subjects COACC was close to $\mathrm{V}_{\mathrm{O} 2 \max }$ and thus could not be determined.

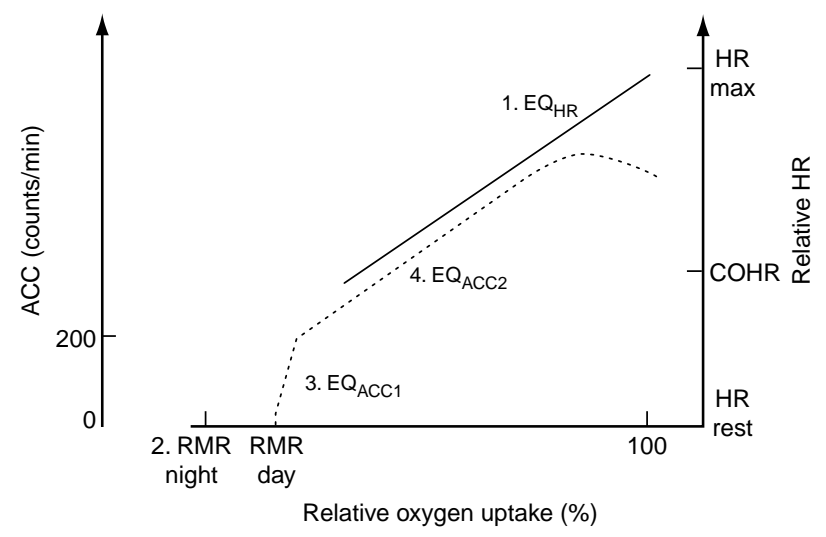

Fig. 2. Characteristics of the proposed analysis model. For details of the four formulas (1-4), see this page. - - - Accelerometry (ACC); - - , heart rate $(\mathrm{HR})$. COACC, accele rometer cut-off point; COHR, heart rate cut-off point.
Proposed new formula for calculating total energy expenditure

The characteristics of the data propose the following formulas to derive EE from data obtained in a free-living situation, employing RMR, ACC and HR values.

Above COHR. For calculating $\mathrm{V}_{\mathrm{O} 2}$, and subsequently EE, at exercise intensities above COHR, the following formula is used:

$$
\text { Formula } \mathrm{EQ}_{\mathrm{HR}}: \mathrm{EE}_{\mathrm{HR}}=\text { beats } / \min \times \beta_{\mathrm{HR}}+\alpha_{\mathrm{HR}}
$$

The constants $\beta_{\mathrm{HR}}$ and $\alpha_{\mathrm{HR}}$ represent the slope and intercept of the linear portion of the $\mathrm{HR}-\mathrm{V}_{\mathrm{O} 2}$ relationship, derived from the calibration test.

Below COHR. For calculating EE below COHR, three different formulas are used, due to ACC and HR values.

When ACC is 0 and no HR value is obtained (subjects were instructed to take off devices during sleep), EE is calculated from Formula 2 - RMR:

$$
\text { Formula : } \mathrm{EE}_{\mathrm{SLEEP}}=\mathrm{RMR}
$$

When ACC is between 0 and 200 counts/min EE is calculated from Formula 3:

$$
\text { Formula } \mathrm{EQ}_{\mathrm{ACC} 1}: \mathrm{EE}_{\mathrm{ACC} 1}=\text { Counts } / \min \times \beta_{\mathrm{ACC} 1}+\alpha_{\mathrm{ACC} 1}
$$

When ACC is between 200 and corresponding ACC at COHR, Formula 4 is used for EE calculation:

$$
\text { Formula } \mathrm{EQ}_{\mathrm{ACC} 2}: \mathrm{EE}_{\mathrm{ACC} 2}=\text { counts } / \min \times \beta_{\mathrm{ACC} 2}+\alpha_{\mathrm{ACC} 2}
$$

The constants $\beta_{\mathrm{ACC}}$ and $\alpha_{\mathrm{ACC}}$ in Formulas 3 and 4 represent the slope and intercept of the linear portion of the $\mathrm{ACC}-\mathrm{V}_{\mathrm{O} 2}$ relationship.

Total time (TT) spent at the different levels is calculated and by applying these formulas EE can be calculated for each of the intensity portions. To compensate for the thermic effect of feeding, which constitutes approximately $10 \%$ of the TEE according to Poehlman (1989), the total calculated EE must be multiplied by a factor of $1 \cdot 1$. The reason for this is to allow comparison between the DLW method, which can detect the thermal effect of feeding, and the new method that is unable to do so. Combining the four formulas results in the following formula for calculation of TEE (see also Fig. 3):

$$
\begin{aligned}
\mathrm{TEE}= & 1 \cdot 1 \times\left(\mathrm{EQ}_{\mathrm{HR}} \times \mathrm{TT}_{\mathrm{HR}}+\mathrm{EQ}_{\mathrm{ACC} 1} \times \mathrm{TT}_{\mathrm{ACC} 1}+\mathrm{EQ}_{\mathrm{ACC} 2}\right. \\
& \left.\times \mathrm{TT}_{\mathrm{ACC} 2}+\mathrm{RMR} \times \mathrm{TT}_{\mathrm{RMR}}\right)
\end{aligned}
$$

By individual calibration equations from the first part of the study and by using the TEE formula, TEE over the $14 \mathrm{~d}$ test period for each subject is calculated. Additionally, TEE was also calculated according to the FLEX-HR concept and from motion sensor data alone. Individual values for the four methods are shown in Table 4. Space dilution ratio and dilution spaces from the DLW analysis is presented in Table 5. Bland-Altman plots illustrate the relationship between the mean and the difference of methods tested and the DLW method (see Fig. 4). As indicated in Fig. 4, TEE and PAEE/kg calculated from the HR-ACC and the ACC methods show no significant difference compared with the criterion method. The FLEX-HR method significantly underestimates TEE and PAEE/kg compared with TEE from the DLW method. Pearson correlations of the mean and the rooted square of the difference show that the data are not heteroscedastic (HR-ACC $v$. DLW, $r 0 \cdot 267, P=0.523$; FLEX-HR $v$. DLW, $r 0.620, P=0 \cdot 101$; ACC $v$. DLW, $r$ 0.037, $P=0.931)$. Model precision was examined using 


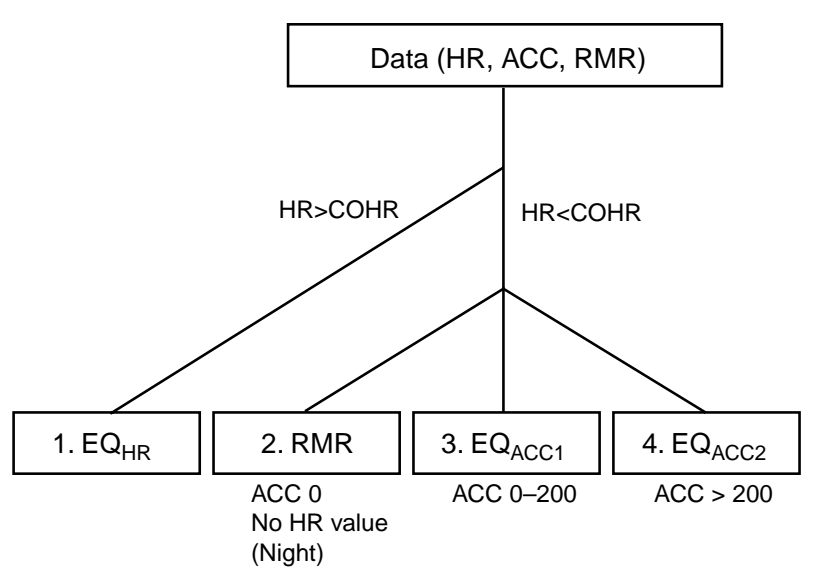

Fig. 3. Proposed data analysis model. (1) $E Q_{H R}$, regression equation $V_{\mathrm{O}_{2}-}$ $\mathrm{HR}$; (2) RMR; (3) $E Q_{A C C 1}$, lower regression equation $V_{O 2}-A C C$; (4) $E Q_{A C C 2}$, higher regression equation $\mathrm{V}_{\mathrm{O}_{2}}-\mathrm{ACC}$. $\mathrm{ACC}$, accelerometry; $\mathrm{COHR}$, heart rate cut-off point; HR, heart rate.

RMSE with $95 \%$ CI (TEE HR-ACC, RMSE 2.99, $95 \%$ CI 0.07, 5.91; TEE FLEX-HR, RMSE 3.99, $95 \%$ CI 1.05, 6.93; TEE ACC, RMSE $2.99,95 \%$ CI $0.53,5.45)$. CI values indicate that there are no differences in model precision between the models. The relative contribution in time and EE derived from the different formulas is presented in Table 6. No significant differences in body composition or body weight $(P=0.945)$ were observed between pre- and post-test values.

\section{Discussion}

It is a well-known fact, also illustrated in Fig. 1, that HR at very low exercise intensities is sensitive to non-energy-related factors, leading to a deviation from the linear $\mathrm{HR}-\mathrm{V}_{\mathrm{O} 2}$ relationship obtained at higher exercise levels. Fig. 1 also shows that at intensities above a cut-off point (COACC) the ACC counts level off. This finding is also supported in a recent article by Brage et al. (2003), who showed that at high running intensities ACC counts do not increase with increasing rate of work, presumably due to relatively constant vertical acceleration in running at different velocities. Another possible explanation could be that at these running velocities speed is controlled mainly by an increase in stride length rather than an increase in frequency (Åstrand \& Rodahl, 1986). It is also unclear whether the built-in frequency filter disturbs the measurement. Thus, the use of HR may overestimate EE at low intensities, while use of ACC may underestimate EE at PA levels above COACC. The latter makes the use of the ACC method for evaluating $\mathrm{PA}$ at high exercise levels questionable.

The characteristics of the new model to calculate TEE, using RMR and the HR and ACC values at increasing $\mathrm{V}_{\mathrm{O} 2}$, are illustrated in Fig. 2 (see also Formula 5). Applying these data we suggest an analysis model for estimating total EE using ACC combined with HR telemetry and RMR. Four sets of data are used:

1. Above $\mathrm{COHR}, \mathrm{EE}$ was calculated using a $\mathrm{HR}-\mathrm{V}_{\mathrm{O} 2}$ equation $\left(\mathrm{EQ}_{\mathrm{HR}}\right)$, obtained from the calibration test. At these PA levels, the relationship between $\mathrm{HR}$ and $\mathrm{V}_{\mathrm{O} 2}$ shows a strong linearity. Nevertheless, factors such as mode of activity, hydration status, altitude, ambient temperature, humidity and psychological stress should still be considered. However, in a daily living situation, the variability of those factors, apart from mode of activity, is fairly small and is therefore of minor importance. Below COHR, data can be divided into three subsets in reference to the accelerometer output.

2. When the ACC reading is equal to zero and no HR value is obtained (at night) the EE is assumed to be equivalent to RMR. Seale \& Conway (1999) showed that this assumption is also appropriate when overnight EE is calculated. Thus, separating the sleep and the non-sleeping rest periods is not required. Individually measured RMR should preferably be used rather than calculated in order to reduce possible errors caused by the use of standardized formulas.

3. During standing and sometimes even during sitting there are some body movements that can be detected by ACC and, hence, be incorporated in the $\mathrm{EQ}_{\mathrm{ACC} 1}$ formula. During nonsleeping hours estimation errors may occur due to the method's inability to perceive whether the subject is lying down, seated or standing. Thus, when ACC is in the range 0-200 counts/min and $\mathrm{HR}<\mathrm{COHR}$, the $\mathrm{ACC}-\mathrm{V}_{\mathrm{O} 2}$ equation $\left(\mathrm{EQ}_{\mathrm{ACC} 1}\right)$ should be used to convert ACC counts to EE.

Table 4. Total energy expenditure (TEE) and physical activity energy expenditure per $\mathrm{kg}$ (PAEE/kg) from different methods and RMR for all subjects of the validation study $(n 8)$

\begin{tabular}{|c|c|c|c|c|c|c|c|c|c|}
\hline \multirow[b]{2}{*}{ Subject } & \multicolumn{2}{|c|}{ DLW } & \multicolumn{2}{|c|}{$\mathrm{HR}-\mathrm{ACC}$} & \multicolumn{2}{|c|}{ FLEX-HR } & \multicolumn{2}{|c|}{ ACC } & \multirow[b]{2}{*}{$\begin{array}{l}\text { RMR } \\
(\mathrm{MJ} / \mathrm{d})\end{array}$} \\
\hline & $\begin{array}{l}\text { TEE } \\
(\mathrm{MJ} / \mathrm{d})\end{array}$ & $\begin{array}{l}\text { PAEE/kg } \\
(\mathrm{kJ} / \mathrm{kg} \text { per d) }\end{array}$ & $\begin{array}{l}\text { TEE } \\
(\mathrm{MJ} / \mathrm{d})\end{array}$ & $\begin{array}{l}\text { PAEE/kg } \\
\text { (kJ/kg per d) }\end{array}$ & $\begin{array}{l}\text { TEE } \\
(\mathrm{MJ} / \mathrm{d})\end{array}$ & $\begin{array}{l}\mathrm{PAEE} / \mathrm{kg} \\
(\mathrm{kJ} / \mathrm{kg} \text { per d) }\end{array}$ & $\begin{array}{l}\text { TEE } \\
(\mathrm{MJ} / \mathrm{d})\end{array}$ & $\begin{array}{l}\text { PAEE/kg } \\
(\mathrm{kJ} / \mathrm{kg} \text { per d) }\end{array}$ & \\
\hline 1 & $12 \cdot 7$ & 37.4 & $18 \cdot 1$ & $100 \cdot 8$ & 13.9 & $51 \cdot 6$ & $15 \cdot 6$ & $71 \cdot 8$ & 6.9 \\
\hline 2 & $10 \cdot 8$ & $66 \cdot 1$ & $11 \cdot 2$ & $72 \cdot 6$ & 7.5 & $17 \cdot 6$ & 9.6 & 48.5 & 5.7 \\
\hline 3 & $18 \cdot 1$ & 55.4 & $23 \cdot 3$ & 94.6 & $12 \cdot 8$ & $15 \cdot 8$ & $23 \cdot 1$ & $92 \cdot 7$ & $9 \cdot 6$ \\
\hline 4 & $11 \cdot 7$ & $61 \cdot 1$ & $11 \cdot 1$ & 53.0 & 9.0 & 25.7 & $8 \cdot 2$ & $15 \cdot 1$ & $6 \cdot 3$ \\
\hline 5 & $17 \cdot 1$ & 93.0 & $20 \cdot 1$ & $127 \cdot 4$ & $12 \cdot 0$ & $35 \cdot 3$ & $19 \cdot 2$ & $116 \cdot 7$ & 8.0 \\
\hline 6 & $13 \cdot 4$ & 64.5 & $15 \cdot 2$ & $87 \cdot 1$ & 9.6 & $17 \cdot 9$ & $13 \cdot 4$ & 64.5 & $7 \cdot 3$ \\
\hline 7 & $16 \cdot 4$ & $116 \cdot 1$ & $15 \cdot 0$ & $97 \cdot 3$ & $11 \cdot 2$ & 44.9 & $12 \cdot 3$ & $60 \cdot 0$ & $7 \cdot 1$ \\
\hline 8 & $10 \cdot 4$ & $46 \cdot 3$ & $10 \cdot 9$ & $52 \cdot 3$ & $7 \cdot 1$ & $2 \cdot 2$ & $12 \cdot 2$ & $70 \cdot 4$ & $6 \cdot 2$ \\
\hline Mean & $13 \cdot 8$ & 67.5 & $15 \cdot 6$ & $85 \cdot 6$ & $10 \cdot 4$ & $26 \cdot 4$ & $14 \cdot 2$ & 67.5 & $7 \cdot 2$ \\
\hline SD & 3.0 & $25 \cdot 5$ & $4 \cdot 6$ & $25 \cdot 5$ & 2.5 & $16 \cdot 5$ & $5 \cdot 0$ & 29.9 & 1.3 \\
\hline RMSE & & & $2.99^{\star}$ & $31 \cdot 1^{*}$ & $3.99^{*}$ & $47 \cdot 3^{*}$ & $2.99^{*}$ & $34 \cdot 1^{*}$ & \\
\hline
\end{tabular}

ACC, accelerometry; DLW, doubly labelled water; FLEX-HR, ??? heart rate; HR, heart rate; RMSE, root mean square error of the difference between methods. ${ }^{*}$ RMSE was significantly different from $0(95 \% \mathrm{Cl})$.

For details of subjects and procedures, see p. 632. 
Table 5. Dilution spaces and space dilution ratios from the doubly labelled water analysis $(n 8)$

\begin{tabular}{lccc}
\hline Subject & $N_{\mathrm{D}}(\mathrm{kg})$ & $N_{\mathrm{O}}(\mathrm{kg})$ & $N_{\mathrm{D}}: N_{\mathrm{O}}$ \\
\hline 1 & 46.94 & 45.49 & 1.032 \\
2 & 36.92 & 35.57 & 1.038 \\
3 & 61.75 & 59.85 & 1.032 \\
4 & 41.65 & 39.74 & 1.048 \\
5 & 50.76 & 48.7 & 1.042 \\
6 & 48.92 & 46.92 & 1.043 \\
7 & 40.38 & 39.11 & 1.032 \\
8 & 41.51 & 40.47 & 1.026 \\
Mean & 46.10 & 44.48 & 1.037 \\
SD & 7.87 & 7.63 & 0.007 \\
\hline
\end{tabular}

$N_{\mathrm{D}}$, pool size ${ }^{2} \mathrm{H} ; N_{\mathrm{O}}$, pool size ${ }^{18} \mathrm{O} ; N_{\mathrm{D}}: N_{\mathrm{O}}$, space dilution ratio. For details of procedures, see p. 632 .

4. When $\mathrm{ACC}>200$ counts $/ \mathrm{min}$ and $\mathrm{HR}<\mathrm{COHR}$, the $\mathrm{ACC}-\mathrm{V}_{\mathrm{O} 2}$ equation $\left(\mathrm{EQ}_{\mathrm{ACC} 2}\right)$ is used.

The main benefit of this approach compared with the FLEX-HR method is that the EE of the time spent at lower intensities
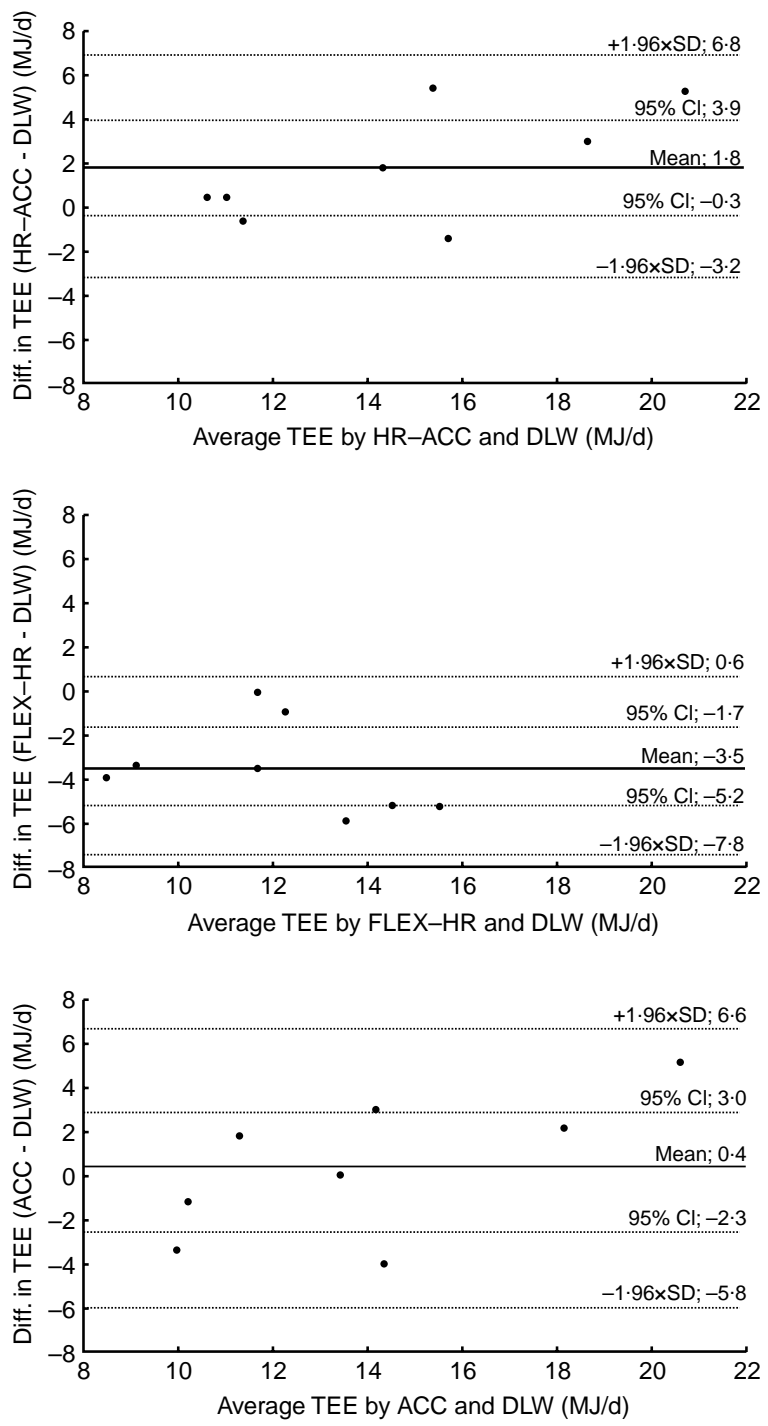

(below COHR) can be derived with a higher resolution compared with the FLEX-HR method, which simply replaces low exercise level data with RMR.

Due to the low number of subjects and the unbalanced gender distribution no conclusions can be drawn regarding possible variation of the new methods' accuracy caused by factors such as gender, body composition and fitness. The most critical part of the calculation of TEE during $24 \mathrm{~h}$ in all subjects is the substantial amount of time spent at low PA levels - that is, in essence $<\mathrm{COHR}$. It is obvious that calculation of EE of a period, which in most cases amounts to $90 \%$ and even more of a person's TT, must be done with caution. Hence, using FLEX-HR and FLEX-HR +10 beats/ min in calculating TEE may induce errors, which will have large consequences. However, it should be emphasized that the new analysis method also has the same problems as the older calculations such as not discriminating between some specific modes of exercise, level or uphill walking, hydration effects etc., due to the fact that the same basic measurements are used. In the present study we found a clear underestimation in TEE FLEX-HR compared with TEE DLW. This is likely due to the fact that, in this
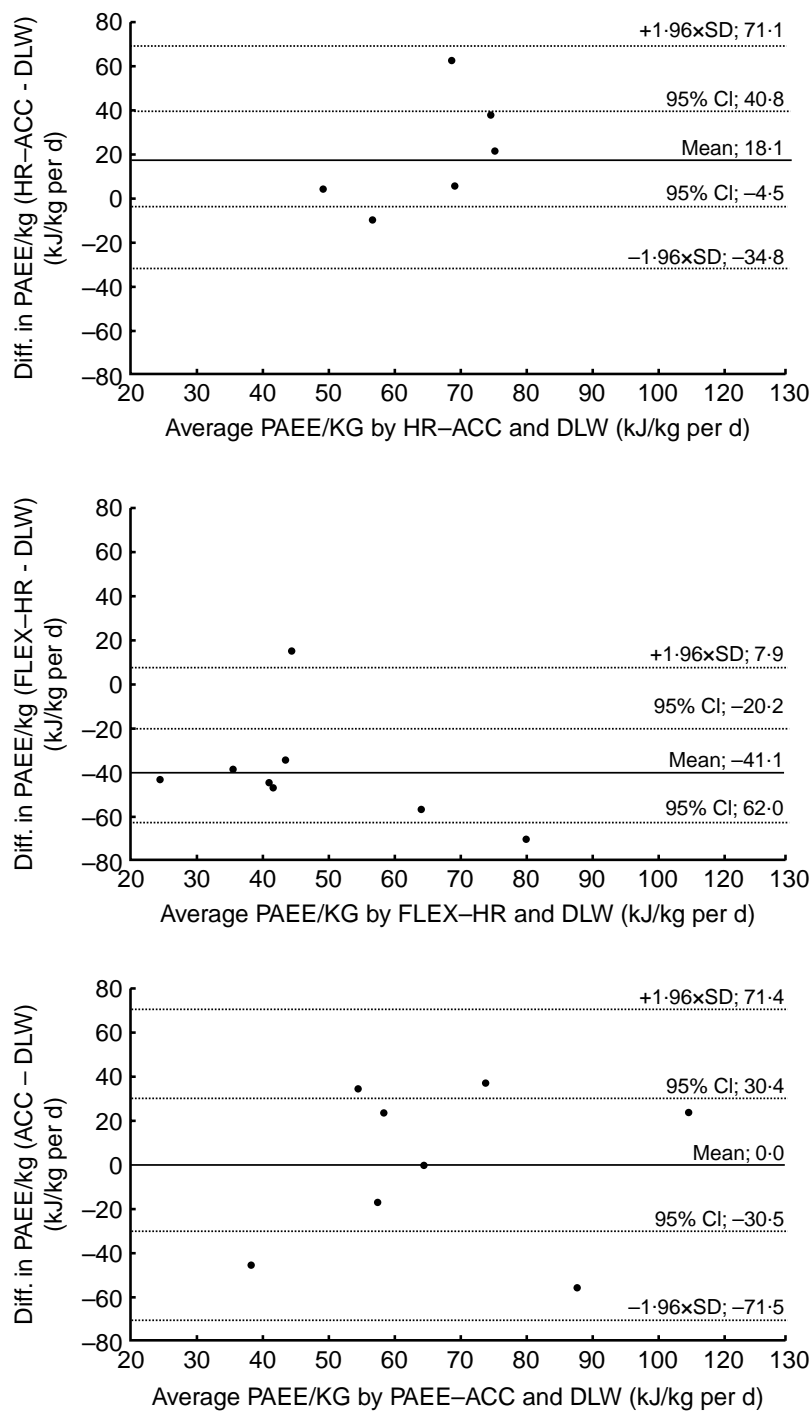

Fig. 4. Bland-Altman plots of differences between measured and estimated total energy expenditure (TEE) and physical activity energy expenditure per kg $(\mathrm{PAEE} / \mathrm{kg})$. — - mean of the difference; - - -, $95 \% \mathrm{Cl}$ and $1.96 \times \mathrm{SD}$. ACC, accelerometry; DLW, doubly labelled water; HR, heart rate. 
Table 6. Relative contribution to energy expenditure obtained from the four different formulas†

\begin{tabular}{|c|c|c|c|c|c|c|c|c|}
\hline & \multicolumn{2}{|c|}{ RMR } & \multicolumn{2}{|c|}{$\mathrm{EQ}_{\mathrm{ACC} 1}$} & \multicolumn{2}{|c|}{$\mathrm{EQ}_{\mathrm{ACC2}}$} & \multicolumn{2}{|c|}{$E Q_{H R}$} \\
\hline & \%TT & $\% \mathrm{EE}$ & $\%$ TT & $\%$ EE & $\%$ TT & $\% \mathrm{EE}$ & \%TT & $\% \mathrm{EE}$ \\
\hline 1 & $40 \cdot 0$ & $20 \cdot 7$ & 38.6 & 34.5 & $14 \cdot 2$ & $19 \cdot 2$ & $7 \cdot 2$ & $25 \cdot 6$ \\
\hline 2 & 29.4 & $16 \cdot 3$ & $47 \cdot 3$ & 37.8 & $16 \cdot 8$ & $24 \cdot 6$ & 6.5 & 21.4 \\
\hline 3 & 39.7 & $17 \cdot 9$ & 38.9 & $40 \cdot 8$ & $15 \cdot 2$ & $24 \cdot 3$ & $6 \cdot 3$ & $18 \cdot 2$ \\
\hline 4 & $30 \cdot 8$ & $19 \cdot 3$ & 47.9 & 29.9 & 13.1 & $19 \cdot 0$ & $8 \cdot 2$ & 31.6 \\
\hline 5 & 29.0 & $15 \cdot 3$ & 45.7 & $37 \cdot 0$ & 14.7 & 23.4 & $10 \cdot 6$ & $27 \cdot 1$ \\
\hline 6 & 32.8 & $17 \cdot 1$ & $41 \cdot 3$ & 36.0 & $18 \cdot 9$ & 26.4 & 7.0 & $21 \cdot 0$ \\
\hline 7 & $36 \cdot 7$ & $19 \cdot 6$ & 28.0 & $22 \cdot 1$ & $19 \cdot 4$ & 21.4 & $15 \cdot 9$ & 37.0 \\
\hline 8 & 31.6 & $19 \cdot 1$ & $53 \cdot 3$ & $52 \cdot 2$ & 13.7 & 24.9 & 1.4 & 3.8 \\
\hline Mean & 33.7 & $18 \cdot 2$ & $42 \cdot 6$ & $36 \cdot 3$ & $15 \cdot 8$ & 22.9 & 7.9 & $23 \cdot 2$ \\
\hline SD & 4.5 & $1 \cdot 8$ & $7 \cdot 7$ & 8.6 & 2.4 & $2 \cdot 7$ & $4 \cdot 1$ & 9.9 \\
\hline
\end{tabular}

$\% \mathrm{EE}$, percentage of energy expenditure; \% $\mathrm{TT}$, percentage of total time.

†For details of formulas, see p. 632.

group, $85-95 \%$ of the subjects' time is spent at intensity levels below COHR/FLEX-HR. By assuming that all this EE above RMR but below COHR is substituted by RMR will cause major errors. The advantage of the proposed method is the use of ACC combined with measured RMR, which enhances the precision of the EE calculations during a substantial period of daily physical exercise $(<\mathrm{COHR})$ at which HR recordings is less accurate. Using this method, an accurate RMR measurement is crucial since it has a major role in the TEE calculations. The use of individually acquired RMR has a possible advantage compared with RMR calculated from standardized formulas. However, the RMR measurement is also a possible source of error. An erronous RMR measurement could give a falsely high TEE. The large difference between TEE DLW and TEE HR-ACC in subject 1 (Table 4) is most likely caused by an overestimation in RMR.

It must be emphasized that the COHR can be difficult to calculate or graphically estimate. However, this might not be a problem, since the accuracy of the present method is not dependent on an exact value of COHR. The fact that there is a rather long overlap in linearity between COHR and COACC opens up the possibility of increasing the accuracy of the calculations. The main reason why the COHR was increased with 10 beats/min is that we wanted to ensure that the nonlinear portion of the $\mathrm{V}_{\mathrm{O} 2}-\mathrm{HR}$ relationship at lower exercise intensities was avoided. Any HR value above COHR but lower than the HR value at COACC is applicable. In addition, since the COHR and COACC show large individual variations general cut-off points cannot be determined, they must be individually acquired.

The thermic effect of feeding is detected by the DLW method but not by the HR-ACC method. Hence, as discussed earlier, in order to obtain TEE the calculated EE must be multiplied with a factor of $1 \cdot 1$. However, the magnitude of the increase in TEE caused by the thermal effect of feeding may be affected by factors such as type of food ingested, number of meals, etc. In addition, little is known about the magnitude of the thermal effect of feeding at different levels of EE. Despite the fact that the validation of the new method for calculating TEE was only carried out in eight subjects, depending on the high cost for the DLW method, the results showed that there was no statistical difference between the new method and the DLW method even if there might be larger individual differences. However, using the accelerometer alone produced, in the present study, a mean TEE and PAEE/ $\mathrm{kg}$ that was closer to the values obtained by the criterion method. The variation of the data obtained from ACC alone was larger though. Theoretically, the combined method would have an advantage in more active subjects. This is partly illustrated in subject no. 7, who has the most physically active occupation in the group, with $16 \%$ of his time spent at activity levels above COHR. The TEE values are: $16.4,15.0$ and $12.3 \mathrm{MJ} / \mathrm{d}$ for DLW, HR-ACC and ACC, respectively.

In summary, we suggest an analysis method to calculate TEE in which RMR, HR and ACC values are used. The total formula is:

$$
\begin{aligned}
\mathrm{TEE}= & 1.1 \times\left(\mathrm{EQ}_{\mathrm{HR}} \times \mathrm{TT}_{\mathrm{HR}}+\mathrm{EQ}_{\mathrm{ACC} 1} \times \mathrm{TT}_{\mathrm{ACC} 1}+\mathrm{EQ}_{\mathrm{ACC} 2}\right. \\
& \left.\times \mathrm{TT}_{\mathrm{ACC} 2}+\mathrm{RMR} \times \mathrm{TT}_{\mathrm{RMR}}\right)
\end{aligned}
$$

As seen in the formula, the total $24 \mathrm{~h} \mathrm{EE}$ is calculated as the sum of EE for the TT spent at each of the different PA levels. Due to the thermal effect of feeding, the calculated EE must be multiplied by a factor of 1.1 . With regard to the substantial time most subjects are spending in PA below COHR but with ACC at 0 , this method has an advantage compared with the FLEX-HR method, illustrated in the Bland-Altman plots and the insignificant difference in $24 \mathrm{~h}$ TEE between the proposed method and the criterion measure, the DLW technique.

It is concluded that the new method as well as ACC alone has potential to be used for assessment of TEE in a free-living situation at group level. It must be stated that TEE calculated from the motion sensor alone (TEE ACC), using double linear equations, has an advantage under these circumstances. However, the low number of subjects and the fact that the group is not balanced regarding gender makes further research desirable.

\section{Acknowledgements}

This study received financial support from The Stockholm University College of Physical Education and Sports, The Folksam insurance company, Swedish National Centre for Research in Sports and The Swedish Defence Research Agency (FOI). The authors gratefully acknowledge the assistance of Dr Lars Ellegård and Mrs Elisabeth Gramatkovski for analysing and calculating the DLW results. In addition, the authors would like to thank The Unit for Preventive Nutrition at Novum, Department of Medical Nutrition/Biosciences, Karolinska Institutet, Stockholm, Sweden for equipment support. There are no professional relationships between the authors and companies or manufacturers who will benefit from the results of the present study. 


\section{References}

Åstrand PO \& Rodahl K (1986) Textbook of Work Physiology: Physiological Bases of Exercise. Singapore: McGraw-Hill Book Company.

Atkinson G \& Nevill AM (1998) Statistical methods for assessing measurement error (reliability) in variables relevant to sports medicine. Sports Med 26, 217-238.

Bland JM \& Altman DG (1986) Statistical methods for assessing agreement between two methods of clinical measurement. Lancet 1, 307-310.

Brage S, Brage N, Franks PW, Ekelund U, Wong MY, Andersen LB, Froberg K \& Wareham NJ (2004) Branched equation modeling of simultaneous accelerometry and heart rate monitoring improves estimate of directly measured physical activity energy expenditure. $J$ Appl Physiol 96, 343-351.

Brage S, Wedderkopp N, Franks PW, Bo Andersen L \& Froberg K (2003) Reexamination of validity and reliability of the CSA monitor in walking and running. Med Sci Sports Exerc 35, 1447-1454.

Brodie DA \& Stewart AD (1999) Body composition measurement: a hierarchy of methods. J Pediatr Endocrinol Metab 12, 801-816.

Ceesay SM, Prentice AM, Day KC, Murgatroyd PR, Goldberg GR, Scott W \& Spurr GB (1989) The use of heart rate monitoring in the estimation of energy expenditure: a validation study using indirect whole-body calorimetry. Br J Nutr 61, 175-186.

Davidson L, McNeill G, Haggarty P, Smith JS \& Franklin MF (1997) Free-living energy expenditure of adult men assessed by continuous heart-rate monitoring and doubly-labelled water. Br J Nutr 78, 695-708.

Ekelund U, Sjostrom M, Yngve A, Poortvliet E, Nilsson A, Froberg K, Wedderkopp N \& Westerterp K (2001) Physical activity assessed by activity monitor and doubly labeled water in children. Med Sci Sports Exerc 33, 275-281.

Emons HJ, Groenenboom DC, Westerterp KR \& Saris WH (1992) Comparison of heart rate monitoring combined with indirect calorimetry and the doubly labelled water $(2 \mathrm{H} 2(18) \mathrm{O})$ method for the measurement of energy expenditure in children. Eur J Appl Physiol Occup Physiol 65, 99-103.

Eston RG, Rowlands AV \& Ingledew DK (1998) Validity of heart rate, pedometry, and accelerometry for predicting the energy cost of children's activities. J Appl Physiol 84, 362-371.

Farahmand BY, Ahlbom A, Ekblom O, Ekblom B, Hallmarker U, Aronson D \& Brobert GP (2003) Mortality amongst participants in Vasaloppet: a classical long-distance ski race in Sweden. J Intern Med 253, 276-283.

Freedson PS, Melanson E \& Sirard J (1998) Calibration of the Computer Science and Applications Inc. accelerometer. Med Sci Sports Exerc 30, 777-781.

Haskell WL, Yee MC, Evans A \& Irby PJ (1993) Simultaneous measurement of heart rate and body motion to quantitate physical activity. Med Sci Sports Exerc 25, 109-115.

Heini AF, Minghelli G, Diaz E, Prentice AM \& Schutz Y (1996) Freeliving energy expenditure assessed by two different methods in rural Gambian men. Eur J Clin Nutr 50, 284-289.

Heini A, Schutz Y, Diaz E, Prentice AM, Whitehead RG \& Jequier E (1991) Free-living energy expenditure measured by two independent techniques in pregnant and nonpregnant Gambian women. Am J Physiol 261, E9-E17.

International Atomic Energy Agency. International Dietary Energy Consultancy Group (1990) The Doubly-labelled Water Method for Measuring Energy Expenditure. Technical Recommendations for Use in Humans. NAHRES-4. Vienna: IAEA.
Jensen K, Jorgensen S \& Johansen L (2002) A metabolic cart for measurement of oxygen uptake during human exercise using inspiratory flow rate. Eur J Appl Physiol 87, 202-206.

Johnson RK, Russ J \& Goran MI (1998) Physical activity related energy expenditure in children by doubly labeled water as compared with the Caltrac accelerometer. Int J Obes Relat Metab Disord 22, 1046-1052.

Lee IM, Sesso HD \& Paffenbarger RS Jr (2000) Physical activity and coronary heart disease risk in men: does the duration of exercise episodes predict risk? Circulation 102, 981-986.

Leenders NY, Nelson TE \& Sherman WM (2003) Ability of different physical activity monitors to detect movement during treadmill walking. Int J Sports Med 24, 43-50.

Leenders NY, Sherman WM, Nagaraja HN \& Kien CL (2001) Evaluation of methods to assess physical activity in free-living conditions. Med Sci Sports Exerc 33, 1233-1240.

Manufacturing Technology Inc. (2003) Actigraph Operator's Manual Model 7164 ver 2.2. Fort Walton Beach, FL: MTI.

Melanson EL Jr \& Freedson PS (1995) Validity of the Computer Science and Applications Inc. (CSA) activity monitor. Med Sci Sports Exerc 27, 934-940.

Montoye HJ, Saris WH, Kemper HC \& Washburn RA (1996) Measuring Physical Activity and Energy Expenditure. Champaign, IL: Human Kinetics.

Poehlman ET (1989) A review: exercise and its influence on resting energy metabolism in man. Med Sci Sports Exerc 21, 515-525.

Rennie K, Rowsell T, Jebb SA, Holburn D \& Wareham NJ (2000) A combined heart rate and movement sensor: proof of concept and preliminary testing study. Eur J Clin Nutr 54, 409-414.

Rowlands AV, Thomas PWM, Eston RG \& Topping R (2004) Validation of the RT3 Triaxial Accelerometer for the assessment of physical activity. Med Sci Sports Exerc 36, 518-524.

Seale JL \& Conway JM (1999) Relationship between overnight energy expenditure and BMR measured in a room-sized calorimeter. Eur $J$ Clin Nutr 53, 107-111.

Seale JL, Conway JM \& Canary JJ (1993) Seven-day validation of doubly labeled water method using indirect room calorimetry. $J$ Appl Physiol 74, 402-409.

Siri WE (1956) The Gross Composition of the Body. New York: Academic Press.

Slinde F, Ellegard L, Gronberg AM, Larsson S \& Rossander-Hulthen L (2003) Total energy expenditure in underweight patients with severe chronic obstructive pulmonary disease living at home. Clin Nutr 22, $159-165$.

Strath SJ, Bassett DR Jr, Thompson DL, \& Swartz AM (2002) Validity of the simultaneous heart rate-motion sensor technique for measuring energy expenditure. Med Sci Sports Exerc 34, 888-894.

Thune I \& Furberg AS (2001) Physical activity and cancer risk: doseresponse and cancer, all sites and site-specific. Med Sci Sports Exerc 33, S530-S550, discussion S609-S510.

Trost SG, Ward DS, Moorehead SM, Watson PD, Riner W \& Burke JR (1998) Validity of the computer science and applications (CSA) activity monitor in children. Med Sci Sports Exerc 30, 629-633.

Weir JB (1990) New methods for calculating metabolic rate with special reference to protein metabolism. 1949. Nutrition 6, 213-221.

Westerterp KR, Brouns F, Saris WH \& ten Hoor F (1988) Comparison of doubly labeled water with respirometry at low- and high-activity levels. J Appl Physiol 65, 53-56.

World Health Organization (2003) Diet, Nutrition and the Prevention of Chronic Diseases. Geneva: WHO. 